\title{
Catechol 0-methyl transferase and dopamine D2 receptor gene polymorphisms: evidence of positive heterosis and gene-gene interaction on working memory functioning
}

\author{
M Florencia Gosso ${ }^{* 1,2,3}$, Eco JC de Geus ${ }^{1,3}$, Tinca JC Polderman ${ }^{1,4}$, Dorret I Boomsma ${ }^{1,2,3}$ \\ Peter Heutink ${ }^{1,2,3}$ and Danielle Posthuma ${ }^{1,3}$ \\ ${ }^{1}$ Department of Biological Psychology, Vrije Universiteit, Amsterdam, The Netherlands; ${ }^{2}$ Department of Clinical \\ Genetics, Section of Medical Genomics, VU Medical Center, Vrije Universiteit, Amsterdam, The Netherlands; \\ ${ }^{3}$ Center for Neurogenomics and Cognitive Research - CNCR, Vrije Universiteit, Amsterdam, The Netherlands; \\ ${ }^{4}$ Department of Child and Adolescent Psychiatry, Erasmus University Rotterdam, Rotterdam, The Netherlands
}

The COMT Val ${ }^{108 / 158}$ Met polymorphism has been extensively studied in relation to individual differences in working memory (WM) performance. The present study tested the association of the COMT Val ${ }^{108 / 158} \mathrm{Met}$ polymorphism with WM performance in two independent family-based Dutch samples: 371 children (mean age 12.4 years) and 391 adults (mean age 36.2 years). A significant association was found between the COMT polymorphism and WM scores in the combined adult and young cohorts. The association reflected positive heterosis such that the Met/Met and Val/Val homozygotes did not perform as well as the Met/Val heterozygotes on the WM tasks. A secondary analysis was conducted in which a DRD2-tagging SNP (rs2075654) was tested for an interactive effect with the COMT polymorphism on WM performance. A significant interactive effect of the DRD2 and COMT genes was found such that heterosis was present only in the $D R D 2$ genotype that has been linked to lower receptor density. Our results support previous findings that WM performance needs an optimal level of dopamine signaling within the PFC. This optimum level depends on enzymatic activity controlling dopamine level as well as dopamine receptor sensitivity, both of which may differ as a function of age and genotype. We conclude that the effects of a single polymorphism in a dopaminergic gene on a well-defined cognitive trait may easily remain hidden if the interaction with age and other genes in the pathway are not taken into account.

European Journal of Human Genetics (2008) 16, 1075-1082; doi:10.1038/ejhg.2008.57; published online 2 April 2008

Keywords: genetic association; epistasis; cognitive ability

*Correspondence: Dr M Florencia Gosso, Department of Biological Psychology, Vrije Universiteit, Van der Boechorststraat 1, Amsterdam 1081 BT, The Netherlands.

Tel: + 3120 5988793; Fax: + 3120 5988832;

E-mail: mf.gosso@vumc.nl

Received 21 August 2007; revised 5 January 2008; accepted 5 February 2008; published online 2 April 2008
Introduction

Working memory (WM) is a fundamental component of human intelligence. ${ }^{1,2}$ It refers to the processes that support the short-term maintenance or manipulation of relevant information in the presence of distracting irrelevant information. Nonhuman primates physiology and human functional imaging studies support a critical involvement of the prefrontal cortex (PFC) in WM. ${ }^{3,4}$ The PFC is the primary target of extensive dopamine (DA) 
projections from the midbrain, and several lines of evidence suggest that the frontal DA level is a critical modulator of WM performance. ${ }^{1,5}$ Hence, genes involved in dopaminergic pathway metabolism have been of particular interest to explain individual differences in WM performance. ${ }^{6-11}$ Amongst these, the catechol-Omethyltransferase (COMT) gene has been studied the most extensively. The COMT gene is located on chromosome 22q11, and contains six exons. ${ }^{12}$ It is involved in enzymatic activity that degrades DA, norepinephrine, and epinephrine. ${ }^{13}$ Two promoters encoding different isoforms, a membrane-bound COMT (MB-COMT) and a soluble COMT (S-COMT), are known. Both transcripts start at exon 3. ${ }^{14}$ Differential expression and activity profiles have been well characterized, MB-COMT is predominantly expressed in brain neurons, ${ }^{15}$ whereas S-COMT is predominantly expressed in other tissues, such as liver, blood, and kidney. ${ }^{14}$ The human MB-COMT plays a crucial role in regulation of DA signaling at the PFC level. It contains a common functional single-nucleotide polymorphism (SNP) (rs4680) that substitutes a Val for a Met residue at codon 158 (see Figure 1).

The Met allele encodes an enzyme with relatively lower activity, ${ }^{16}$ and is thought to be specific to humans; as no equivalent polymorphism has been found in any other species. ${ }^{17}$ Decrease in enzyme activity present in Met/Met individuals, compared to individuals homozygous for the Val allele, leads to a relatively higher DA availability, whereas Met/Val heterozygous display an intermediate enzyme activity. ${ }^{18}$ Because frontal DA level is a critical modulator of WM processes, the decreased COMT activity of Met carriers might be beneficial to their cognitive performance. In line with this, Savitz et al ${ }^{10}$ found that 20 of the 26 studies on the association between the COMT $\mathrm{Val}^{108 / 158}$ Met polymorphism and cognitive function reported a significant association. All but two of these studies suggested that the low-activity Met allele yields better performance on cognitive tasks that have a WM component. However, these studies were often based on small and/or clinical samples (ADHD in children; schizophrenia in adults) and no significant association to WM was found in a much larger sample of healthy adult males. ${ }^{19}$ In addition, Mattay et $a l^{20}$ have shown that the role of the

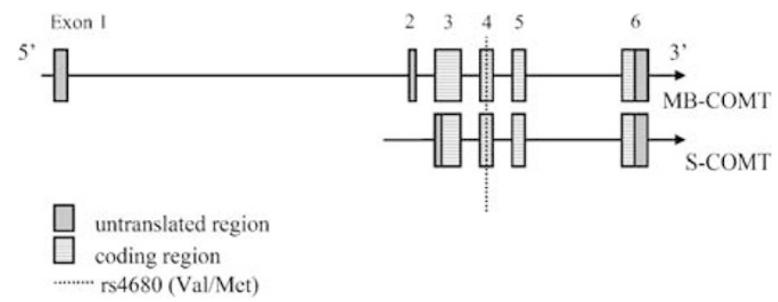

Figure 1 COMT gene and functional single-nucleotide polymorphism (SNP) rs4680 on 22q11.21.
COMT Val ${ }^{108 / 158} \mathrm{Met}$ polymorphism in PFC function, particularly in WM performance, is not straightforward. Although homozygous individuals for the Met allele perform significantly better than individuals homozygous for the Val allele, when the Met homozygotes are given DA agonists their response actually deteriorates. In contrast, the response of the 'dopamine-poor' Val homozygotes improves with DA agonists. This suggests that the relation between DA availability at the PFC level as indexed by COMT activity and WM performance is not linear, but instead follows an inverted-U shape.

DA signaling, furthermore, is not only dependent on the availability of DA, but also on the efficiency of the DA receptor and its downstream signaling cascade. Because of their importance in reward processing, dopaminergic receptors, in particular the DA D2 receptor gene (DRD2), have been studied extensively in addiction research. ${ }^{21}$ The DRD2 gene is located on chromosome 11 at q22-q23 (see Figure 2). A DRD2 Taq IA variant, a restriction fragment length polymorphism (RFLP), located on the $3^{\prime}$ untranslated region ( $\left.3^{\prime} \mathrm{UTR}\right)$ of the DRD2 gene, is associated with altered receptor density. ${ }^{22}$ Individuals with the A1 allele show a $30-40 \%$ reduction in D2 DA receptor density compared with those homozygous for the A2 allele. ${ }^{22,23}$

Recently, Reuter et $\mathrm{al}^{24}$ conducted an association analysis using an adult cohort enriched for COMT and DRD2 homozygotes. They found a significant interaction between DRD2 Taq IA and COMT Val ${ }^{108 / 158}$ Met polymorphisms, and performance on response interference on the Stroop color-word conflict task. Met homozygotes performed better than $\mathrm{Val}$ allele carriers, but only if they had the $D R D 2$ genotype associated with low receptor density. In fact, Met homozygotes also bearing two DRD2 A2 alleles showed a significantly worse performance compared to all other genotypes. Although response interference and WM are not unitary constructs, we showed a significant correlation $(r=-0.26, P<0.05)$ between these two measures of PFC function. ${ }^{25}$ Hence, we hypothesize that a COMT by DRD2 interaction may also be found for WM performance.

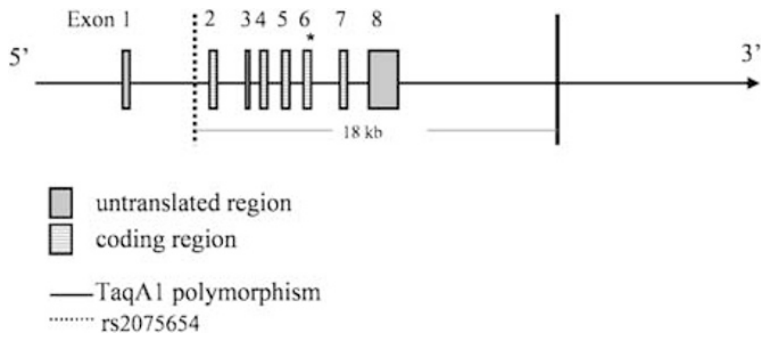

Figure 2 DRD2 gene and tagging SNP rs2075654 near the restriction site Taq A1 on $11 \mathrm{q} 23 .{ }^{*}$ indicates splicing site at exon 6. 
In the present study, which included 762 genotyped subjects, from two independent family-based Dutch samples of 371 (mean age 12.4 years) and 391 (mean age 36.2 years) subjects, respectively, our principal goal was to test for association of the COMT Val ${ }^{108 / 158}$ Met polymorphism with WM performance. The use of a family-based sample made it possible to test for association in a combined within- and between-family design to estimate genetic effects, which are free from spurious effects of population stratification. ${ }^{26}$ As a secondary analysis, we tested for an interactive effect of the COMT Val ${ }^{108 / 158}$ Met polymorphism and genetic variation in the DRD2 gene on WM performance comparable to the effect reported by Reuter et $a l^{24}$ for Stroop interference. Because DA receptor sensitivity has been shown to decline with aging in both animal $^{27}$ and human studies, ${ }^{28}$ our analyses will allow this interaction to be different in children and adults.

\section{Materials and methods Subjects}

All twins and their siblings were part of two larger cognitive studies and were recruited from the Netherlands Twin Registry. ${ }^{29}$ Informed consent was obtained from the participants (adult cohort) or from their parents if they were under 18 years of age (young cohort). The current study was approved by the institutional review board of the VU University Medical Center. None of the individuals tested suffered from severe physical or mental handicaps, as assessed through standard questionnaire.

\section{Young cohort}

The young cohort consisted of 177 twin pairs born between 1990 and 1992, and 55 siblings, ${ }^{30,31}$ of which 371 were available for genotyping. The genotyped twins were 12.4 $(\mathrm{SD}=0.9)$ years of age and the siblings were between 8 and 15 years of age at the time of testing. There were 35 monozygotic male twin pairs (MZM), 28 dizygotic male twin pairs (DZM), 48 monozygotic female twin pairs (MZF), 23 dizygotic female twin pairs (DZF), 26 dizygotic oppositesex twin pairs (DOS), 24 male siblings and 24 female siblings, and 3 subjects form incomplete twin pairs (1 male, 2 females). Participation in this study included a voluntary agreement to provide buccal swabs for DNA extraction.

\section{Adult cohort}

A total of 793 family members from 317 extended twin families participated in the adult cognition study. ${ }^{32}$ Participation in this study did not automatically include DNA collection, however, part of the sample, 276 subjects returned to the lab to provide blood samples, 115 provided buccal swabs through the biobanking project ${ }^{33}$ for DNA extraction. Mean age of the genotyped sample was 36.2 years $(\mathrm{SD}=12.6)$. There were 25 monozygotic male twin pairs (MZM), 15 dizygotic male twin pairs (DZM), 1 DZM triplet, 20 monozygotic female twin pairs (MZF), 28 dizygotic female twin pairs (DZF), 23 dizygotic oppositesex twin pairs (DOS), 29 female siblings, 28 male siblings, and 109 subjects from incomplete twin pairs (41 males, 68 females).

\section{Cognitive testing}

WM tasks were assessed in the young cohort, using the Dutch adaptation of the Wechsler Intelligence Scale for Children-Revised (WISC-R) ${ }^{34}$ consisting of two subtests: arithmetic and digit span. WM performance was indexed as the sum score of the two subtests and corrected for age and sex. The Dutch adaptation of the Wechsler Adult Intelligence Scale III-Revised (WAIS-IIIR) ${ }^{35}$ was used to assess WM performance in the adult cohort and consisted of two subtests taxing WM (arithmetic and letter-number sequencing). WM was indexed as the sum score of arithmetic and letter-number sequencing and corrected for age and sex.

\section{DNA collection and genotyping}

DNA isolation from buccal swabs was performed using a chloroform/isopropanol extraction ${ }^{36}$ DNA was extracted from blood samples using the salting out protocol. ${ }^{37}$ Zygosity was assessed using 11 polymorphic microsatellite markers (Het $>0.80$ ). Genotyping was performed blind to familial status and phenotypic data. Both MZ twins of a pair were included, serving as additional quality control on genotyping. COMT genotyping was performed using fluorogenic probes in the high-throughput $5^{\prime}$-nuclease assay and following manufacturer's recommendations (TaqMan, PE Applied Biosystems, Foster city, CA, USA). For DRD2, instead of the $\mathrm{A} 1$ allele of the Taq IA polymorphism, a tag-SNP (rs2075654) lying $18 \mathrm{~kb}$ downstream of the Taq IA variant was genotyped. LD between rs2075654 and Taq IA was calculated using the CEPH population, which is presumably of similar genetic ancestry to the Dutch population. LD between these two polymorphisms was high $\left(r^{2}=0.65\right.$, LOD score 14.14$)$. In view of the LD between the tag-SNP and Taq IA, we will refer to the T allele as 'A1'. DRD2-SNP genotyping was performed as part of a SNPlex assay, which included multiple other genes, following a tagging approach. ${ }^{38}$ The SNPlex assay was conducted following the manufacturer's recommendations (Applied Biosystems). Here we focus on the DRD2 gene only. Results on cognitive effects of two other genes are described elsewhere. ${ }^{39,40}$

\section{Statistical analyses}

Allele frequencies of the COMT Val ${ }^{108 / 158}$ Met and DRD2 A1/A2 polymorphisms were estimated in both cohorts using Haploview (http://www.broad. mit.edu/mpg/haploview), in which a Hardy-Weinberg test is implemented, based on an exact calculation of the probability of observing a certain number of heterozygotes conditional 
on the number of copies of the minor SNP allele. Familybased genetic association tests were conducted using the program QTDT (http://www.sph.umich.edu/csg/abecasis/ QTDT/), which implements the orthogonal association model proposed by Abecasis et $a l^{41}$ (see also Fulker et $a l^{42}$ extended by Posthuma $e t \mathrm{al}^{43}$ ) This model allows one the decomposition of the genotypic association effect into orthogonal between- $\left(\beta_{\mathrm{b}}\right)$ and within- $\left(\beta_{\mathrm{w}}\right)$ family components and can incorporate fixed effects of covariates and can also model the residual sib-correlation as a function of polygenic or environmental factors. MZ twins can be included and are modeled as such, by adding zygosity status to the data file. They are not informative to the within-family association component (unless they are paired with non-twin siblings) but are informative for the between family component. The between-family association component is sensitive to population admixture, whereas the within-family component is significant only in the presence of true association. Testing for the equality of the $\beta_{\mathrm{b}}$ and $\beta_{\mathrm{w}}$ effects serves as a test of population stratification. If population stratification acts to create a false association, the test for association using the withinfamily component $\left(\beta_{\mathrm{b}}\right)$ is still valid and provides a conservative test of association. If this test is not significant, the between- and within-family effects are equal and the more powerful association test that uses the whole population at once can be applied. The residual sib correlation was modeled as a function of residual genetic variance and non-shared environmental variance. The DRD2 genotype was recoded into carriers $(\mathrm{A} 1+)$ versus non-carriers (A1-). We used one-sided hypothesis testing for the interaction effects as our hypotheses specify the direction of genetic effects.

\section{Results}

In total, 762 subjects were available for SNP genotyping. Based on blind controls and intrapair MZ comparisons, a low genotyping error rate was found $(0.015 \%)$. For the total sample, the success rate was 98.5 and $93.4 \%$ for the COMT $\mathrm{Val}^{108 / 158}$ Met polymorphism in the young and adult cohort, respectively. For DRD2 rs2075654, success rates were 97 and 100\%, 365 adults and 360 children had genotype data for both COMT and DRD2. The distribution of genotype and allele frequencies of the COMT and DRD2 polymorphisms as well as means, standard deviations, and standard errors for WM performance are provided in Table 1. Phenotypic means are provided for the complete phenotypic sample as well as for the genotyped subsamples.

\section{Stratification}

Tests for the presence of population stratification were not significant at the 0.05 level $\left(C O M T: \chi_{(1360)}^{2}=0.937\right.$, $P=0.33 ; \chi_{(1360)}^{2}=0.23, P=0.64 ; \chi_{(1724)}^{2}=1.516, P=0.22$; for children, adults and the combined sample, respectively) $\left(D R D 2: \chi_{(135)}^{2}=0.220, P=0.64 ; \chi_{(1388)}^{2}=0.00, P=0.9976\right.$; $\chi_{(1748)}^{2}=0.084, \quad P=0.77$; for children, adults and the combined sample, respectively), indicating that genotypic effects within families were not significantly different from those observed between families, suggesting that the more powerful population-based association test can be meaningfully interpreted for both COMT and DRD2.

\section{COMT polymorphism}

WM performance was compared across the three possible genotype groups (Met/Met, Met/Val, and Val/Val) suggesting

Table 1 Means and standard deviations WM scores for COMT and DRD2 genotypes

\begin{tabular}{|c|c|c|c|c|c|c|}
\hline Cohort & Genotype & $N$ & Frequency & WM mean & Standard deviation & Standard error of mean \\
\hline \multicolumn{7}{|l|}{ Young } \\
\hline Total phenotypic sample & & 407 & & 22.88 & 4.85 & 0.24 \\
\hline Genotyped sample & & 371 & & 22.90 & 4.89 & 0.25 \\
\hline COMT & Met/Met & 117 & 0.32 & 22.51 & 4.96 & 0.46 \\
\hline \multirow[t]{2}{*}{$N=365$} & Met/Val & 175 & 0.48 & 23.49 & 5.06 & 0.38 \\
\hline & Val/Val & 73 & 0.20 & 22.27 & 4.33 & 0.51 \\
\hline DRD2 & A1A1 & 9 & 0.03 & 23.98 & 2.08 & 0.69 \\
\hline \multirow[t]{2}{*}{$N=360$} & $\mathrm{~A} 1 \mathrm{~A} 2$ & 94 & 0.26 & 23.12 & 5.10 & 0.53 \\
\hline & $\mathrm{A} 2 \mathrm{~A} 2$ & 257 & 0.71 & 22.78 & 4.88 & 0.30 \\
\hline \multicolumn{7}{|l|}{ Adult } \\
\hline Total phenotypic sample & & 793 & & 109.91 & 15.89 & 0.56 \\
\hline Genotyped sample & & 391 & & 109.92 & 15.80 & 0.80 \\
\hline COMT & Met/Met & 112 & 0.31 & 108.48 & 15.73 & 1.49 \\
\hline \multirow[t]{2}{*}{$N=365$} & Met/Val & 168 & 0.46 & 111.51 & 14.89 & 1.16 \\
\hline & Val/Val & 85 & 0.23 & 107.77 & 17.02 & 1.84 \\
\hline DRD2 & $\mathrm{A} 1 \mathrm{~A} 1$ & 16 & 0.04 & 104.96 & 14.66 & 3.67 \\
\hline \multirow{2}{*}{$N=391$} & $\mathrm{~A} 1 \mathrm{~A} 2$ & 109 & 0.27 & 110.76 & 14.25 & 1.36 \\
\hline & $\mathrm{A} 2 \mathrm{~A} 2$ & 266 & 0.69 & 110.36 & 16.32 & 1.00 \\
\hline
\end{tabular}

Note: The WM scores of children and adults are based on different subtests. Although these index the same theoretical construct, the WM scores cannot be compared directly across age cohorts. 
a positive heterosis pattern in both the young and the adult cohorts (see Table 1). Heterosis refers to a situation in which a given trait is significantly greater (or lesser) in individuals heterozygous at a specific gene marker than those homozygous for either allele. We tested for heterosis by adding a non-additive (dominance) genetic component to the population-based analysis in QTDT and testing whether the heterozygous genotypes were associated with better WM performance. A significant heterosis effect was found for the association between COMT Val ${ }^{108 / 158} \mathrm{Met}$ polymorphism and $\mathrm{WM}$ in the adult cohort $\left(\chi_{(1360)}^{2}=4.80\right.$, $P=0.014$ ) even after correction for multiple testing. In the young cohort, the association did not reach significance $\left(\chi_{(1360)}^{2}=1.54, P=0.107\right)$, although the effects were in the same direction as in the adult cohort. The strongest effect was found in the combined sample $\left(\chi_{(1724)}^{2}=5.70\right.$, $P=0.008)$.

\section{DRD2 polymorphism}

No significant main effect was found on the DRD2 rs2075654 tag-SNP and WM performance $\left(\chi_{(1,356)}^{2}=0.42\right.$ $P=0.52 ; \chi_{(1,391)}^{2}=0.04 P=0.84 ;$ and $\chi_{(1749)}^{2}=0.10 P=0.75$, for children, adults, and the combined sample, respectively).

\section{COMT and $D R D 2$ interaction}

Figure 3 plots WM performance against six possible combined genotype groups (Met/Met,A-; Val/Met,A-; Val/ Val,A-; Met/Met;A + ; Val/Met,A+ and Val/Val,A+). The figure suggests that the heterosis found for the COMT gene is entirely limited to subjects with the $D R D 2 \mathrm{~A}+$ genotype, the genotype previously linked to the reduced receptor density. In support of this, a significant interaction effect was detected between the DRD2 and COMT polymorphisms in the combined sample $\left(\chi_{(1699)}^{2}=2.72\right.$, one-sided $\left.P=0.050\right)$, which seemed confined to the adult cohort (see Table 2).
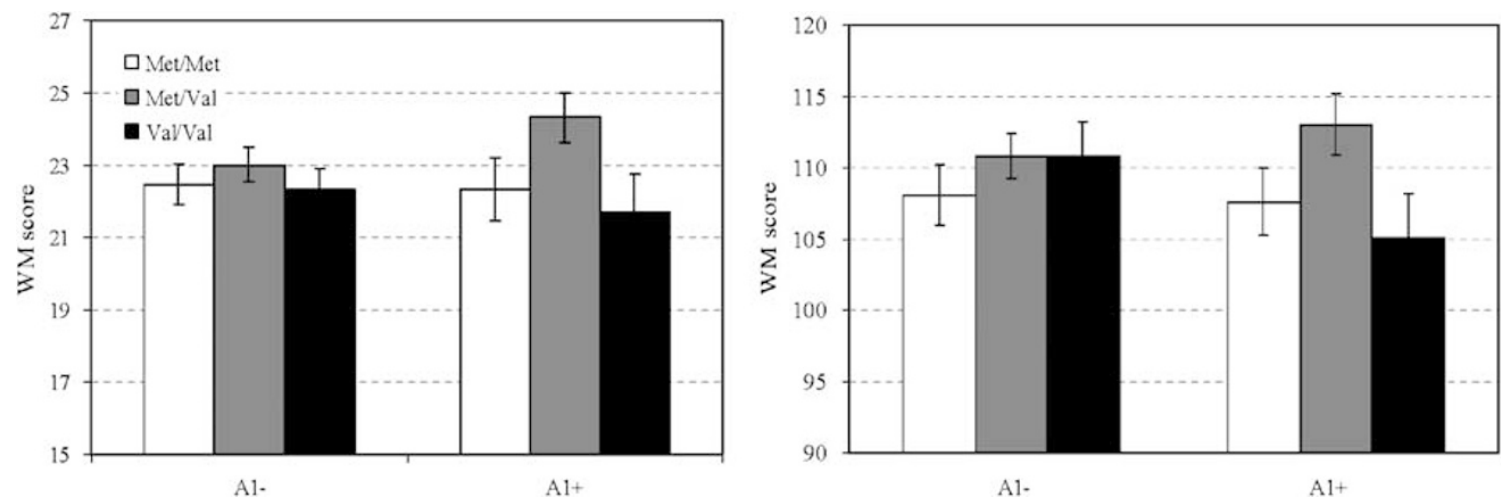

Figure 3 Working memory (WM) means plotted for the six combined genotype groups of the COMT and DRD2 genes for young (left panel) and adult (right panel) cohort. Bars denote standard error. Note: A+ denotes carriers of the A1 allele, whereas A- denotes non-carriers.

Table 2 Results of population-based gene-gene interaction analysis - for COMT Val ${ }^{108 / 158} \mathrm{Met}$, and DRD2 rs2075654 (tagging the TaqA1 polymorphism) for the young, adult, and combined cohorts

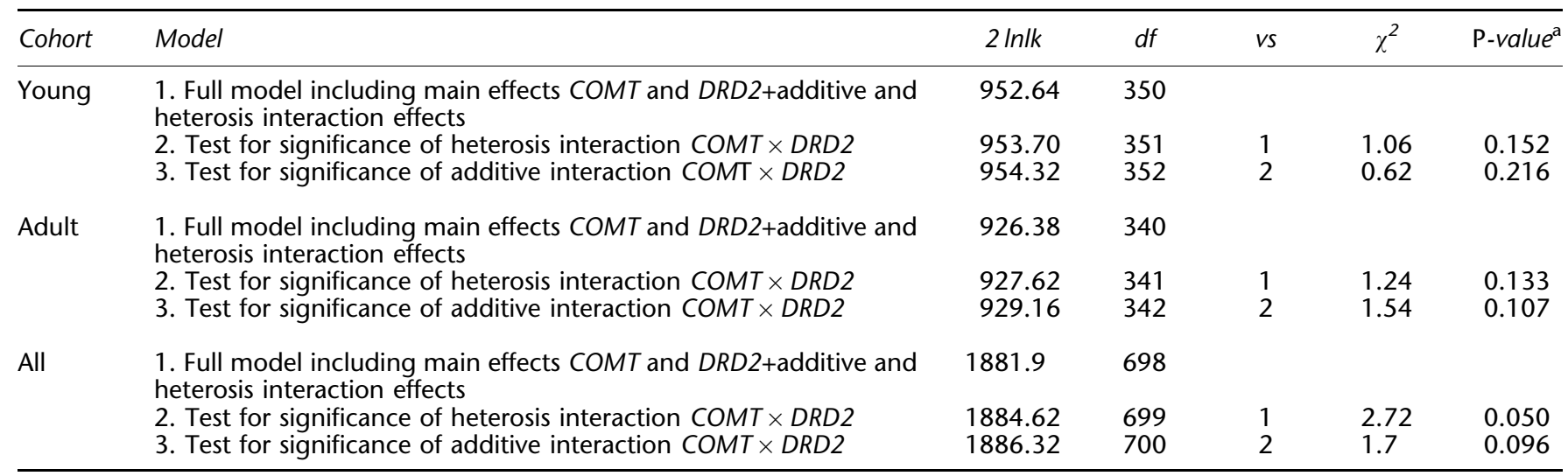

ane-sided $P$-value.

Note: Model 1 = full model, includes a grand mean, main additive and heterosis effects of COMT, a main effect of A1 carriers versus non carriers of $D R D 2$, and additive and heterosis interaction of COMT genotypes $\times$ DRD2 A1 carriers versus non-carriers. Model $2=$ model 1 , except the heterosis interaction. Model $3=$ model 2, except the additive interaction. 


\section{Discussion}

In the present study, we tested the association of the COMT Val ${ }^{108 / 158}$ Met polymorphism with WM performance. A significant association was found in the combined sample with stronger contribution from the adult than the young cohort. The association reflected positive heterosis such that the Met/Val heterozygotes performed better than both $\mathrm{Met} / \mathrm{Met}$ and $\mathrm{Val} / \mathrm{Val}$ homozygotes on the WM tasks. An age-dependent positive heterosis pattern has previously been reported in a longitudinal study by Harriset al. ${ }^{44}$ The COMT genotype was not associated with childhood intelligence measured at the age of 11 years in the Scottish Mental Survey of 1932. At the age of 79 years, COMT genotype was significantly related to differences in verbal declarative memory and to scores on the personality traits of intellect/imagination. For both traits, the elderly Val/ Met heterozygotes had higher scores than both homozygous groups, which echo the pattern of heterosis on WM found in adult cohort. Because the COMT polymorphism has been hypothesized to have a nonlinear effect on DA availability in the prefrontal cortex, ${ }^{20}$ the finding of heterosis is in keeping with the idea that the relationship between DA signaling and cognitive performance follows an inverted U-shaped curve, with both suboptimal and supraoptimal DA activity, impairing prefrontal function. ${ }^{45}$ Burst firing of VTA neurons causes synaptic DA release in pyramidal cells in the PFC. Because these cells contain little DA transporter (DAT), most DA diffuses out of the synaptic cleft to bind to extrasynpatic D1 receptors, where it is inactivated by $C O M T{ }^{46}$ The higher activity Val allele decreases extrasynaptic DA levels and, therefore, D1 activation, shifting the balance in favor of intrasynaptic D2 receptor activation. ${ }^{46,47}$ Cognitive performance may be critically dependent on the $D 1 / D 2$ binding ratio, with a relative lack of $D 1$ signaling causing impulsivity, distractibility, and poor WM performance with schizophrenia at the extreme end. ${ }^{47}$ A relative lack of D2 signaling, on the other hand, may fail to signal the presence of reward information, a signal that is required to engage the PFC in updating its WM system. ${ }^{48}$

The above suggests that the optimum level of DA signaling depends not simply on frontal DA availability, but on its combination with D2 receptor sensitivity. Therefore, individual differences in DA availability as well as $D 2$ receptor sensitivity may come into play during the performance of WM tasks. We tested this expectation in a secondary analysis in which a DRD2 tagging SNP (rs2075654) was tested for an interactive effect with the COMT polymorphism. No significant main effect on WM was found for the rs2075654 tag-SNP in DRD2. However, in the combined cohort, the DRD2 and COMT polymorphisms had a significant interactive effect on WM performance. The interaction suggested that the Met/Val heterozygotes perform better than both Met/Met and $\mathrm{Val} /$ Val homozygotes only when they carry one or two A1 alleles. The A1 alleles have been associated with lower receptor density, suggesting that the U-curve-shaped effect of DA availability on WM performance disappears when receptor density is high. Such a pattern has been previously reported by Reuter et al, ${ }^{24}$ who reported a significant interactive effect between the DRD2 Taq IA and the COMT polymorphisms on the amount of response interference in the Stroop color-word conflict task. Inspection of Figure 3 suggests that the interaction is stronger in the adult than in the young cohort. Although p-values in neither cohort reach formal significance levels, this age difference may be real. Evidence for age-related changes regarding DA metabolism within the PFC has been postulated in both animal $^{27}$ and human studies, ${ }^{28}$ with increased DA metabolism (eg, MAO, COMT) thought to be present at a more mature age. ${ }^{49}$ Furthermore, several lines of evidence showed a decrease of DA receptors with age. ${ }^{50-52}$ When age-related changes in overall levels of DA availability and DA receptor sensitivity are superimposed on the influence of genetic polymorphisms on these levels, a different change in overall DA signaling may occur with age in the various COMT-DRD2 haplotypes. When we add to this that there may be an inverted U-curved relation between DA signaling and WM performance, interactions between age, DRD2, and COMT genes should be the rule rather than the exception.

Clearly, full genetic contribution to dopaminergic variation in frontal executive function will rely on far more complex interactions between multiple receptor (eg, DRD1, $D R D 2$, and DRD4), transporters and enzymatic polymorphisms (eg, DAT, COMT, and MAO). ${ }^{9,53,54}$ Further studies systematically involving such interactions are needed to obtain a clearer overview of the dopaminergic pathway. At the same time, denser SNP coverage of the area under study is needed in genes like DRD2 to reveal the true functional variants, which while tagged, are still undiscovered. In summary, our results are in keeping with previous findings suggesting that WM performance needs an optimal level of DA signaling within the PFC. This optimum level depends on enzymatic activity controlling DA level as well as on DA receptor sensitivity, both of which may differ as a function of age and genotype. We conclude that the effects of a single polymorphism in a dopaminergic gene on a welldefined cognitive trait may easily remain hidden if the interaction with age and other genes in the pathway are not taken into account.

\section{Acknowledgements}

This study was supported by the Universitair Stimulerings Fonds (Grant number 96/22), the Human Frontiers of Science Program (Grant number rg0154/1998-B), the Netherlands Organization for Scientific Research (NWO) Grants 904-57-94 and NWO/SPI 56-46414192. This study was also supported by the Centre for Medical Systems Biology (CMSB), a center of excellence approved by the Netherlands Genomics Initiative/Netherlands Organization for 
Scientific Research (NWO). We thank the families from the Netherlands Twin Registry (NTR) who participated in this study.

\section{References}

1 Conway ARA, Cowan N, Bunting MF, Therriault DJ, Minkhoff SRB: A latent variable analysis of working memory capacity, short-term memory capacity, processing speed, and general fluid intelligence. Intelligence 2002; 30: 163-183.

2 Colom R, Rebollo I, Palacios A, Juan-Espinosa M, Kyllonen PC: Working memory is (almost) perfectly predicted by $g$. Intelligence 2004; 32: 277-296.

3 Curtis CE, D'Esposito M: Persistent activity in the prefrontal cortex during working memory. Trends Cogn Sci 2003; 7: $415-423$.

4 Fuster JM: Network memory. Trends Neurosci 1997; 20: 451-459.

5 Gibbs SE, D'Esposito M: Individual capacity differences predict working memory performance and prefrontal activity following dopamine receptor stimulation. Cogn Affect Behav Neurosci 2005; 5: $212-221$.

6 Brunner HG, Nelen M, Breakefield XO, Ropers HH, van Oost BA: Abnormal behavior associated with a point mutation in the structural gene for monoamine oxidase A. Science 1993; 262: $578-580$.

7 Harmer CJ, McTavish SF, Clark L, Goodwin GM, Cowen PJ: Tyrosine depletion attenuates dopamine function in healthy volunteers. Psychopharmacology (Berl) 2001; 154: 105-111.

8 Malhotra AK, Kestler LJ, Mazzanti C, Bates JA, Goldberg T, Goldman D: A functional polymorphism in the COMT gene and performance on a test of prefrontal cognition. Am J Psychiatry 2002; 159: 652-654.

9 Williams GV, Castner SA: Under the curve: critical issues for elucidating D1 receptor function in working memory. Neuroscience 2006; 139: 263-276.

10 Savitz J, Solms M, Ramesar R: The molecular genetics of cognition: dopamine, COMT and BDNF. Genes Brain Behav 2006; 5: 311-328.

11 Reuter M, Hennig J: Association of the functional catechol-Omethyltransferase VAL158MET polymorphism with the personality trait of extraversion. Neuroreport 2005; 16: 1135-1138.

12 Grossman MH, Emanuel BS, Budarf ML: Chromosomal mapping of the human catechol-O-methyltransferase gene to 22q11.1q11.2. Genomics 1992; 12: 822-825.

13 Axelrod J: O-Methylation of epinephrine and other catechols in vitro and in vivo. Science 1957; 126: 400-401.

14 Tenhunen J, Salminen M, Lundstrom K, Kiviluoto $T$, Savolainen R, Ulmanen I: Genomic organization of the human catechol O-methyltransferase gene and its expression from two distinct promoters. Eur J Biochem 1994; 223: 1049-1059.

15 Matsumoto M, Weickert CS, Akil M et al: Catechol O-methyltransferase mRNA expression in human and rat brain. Evidence for a role in cortical neuronal function. Neuroscience 2003; 116: $127-137$

16 Lotta T, Vidgren J, Tilgmann C et al: Kinetics of human soluble and membrane-bound catechol O-methyltransferase. A revised mechanism and description of the thermolabile variant of the enzyme. Biochemistry 1995; 34: 4202-4210.

17 Palmatier MA, Kang AM, Kidd KK: Global variation in the frequencies of functionally different catechol-O-methyltransferase alleles. Biol Psychiatry 1999; 46: 557-567.

18 Boudikova B, Szumlanski CL, Maidak B, Weinshilboum RM: Human liver catechol-O-methyltransferase pharmacogenetics. Clin Pharmacol Ther 1990; 48: 381-389.

19 Stefanis NC, Van Os J, Avramopoulos D et al: Variation in catechol-o-methyltransferase val158 met genotype associated with schizotypy but not cognition: a population study in 543 young men. Biol Psychiatry 2004; 56: 510-515.

20 Mattay VS, Goldberg TE, Fera F et al: Catechol O-methyltransferase val158-met genotype and individual variation in the brain response to amphetamine. Proc Natl Acad Sci USA 2003; 100: 6186-6191.

21 Comings DE, Blum K: Reward deficiency syndrome: genetic aspects of behavioral disorders. Prog Brain Res 2000; 126: $325-341$.

22 Thompson J, Thomas N, Singleton A et al: D2 dopamine receptor gene (DRD2) Taq1 A polymorphism: reduced dopamine D2 receptor binding in the human striatum associated with the A1 allele. Pharmacogenetics 1997; 7: 479-484.

23 Pohjalainen T, Rinne JO, Nagren K et al: The A1 allele of the human D2 dopamine receptor gene predicts low D2 receptor availability in healthy volunteers. Mol Psychiatry 1998; 3: 256-260.

24 Reuter M, Peters $\mathrm{K}$, Schroeter $\mathrm{K}$ et al: The influence of the dopaminergic system on cognitive functioning: a molecular genetic approach. Behav Brain Res 2005; 164: 93-99.

25 Stins JF, Polderman JC, Boomsma DI, de Geus EJ: Response interference and working memory in 12-year-old children. Child Neuropsychol 2005; 11: 191-201.

26 Laird NM, Lange C: Family-based designs in the age of large-scale gene-association studies. Nat Rev Genet 2006; 7: $385-394$.

27 Lee JJ, Chang CK, Liu IM, Chi TC, Yu HJ, Cheng JT: Changes in endogenous monoamines in aged rats. Clin Exp Pharmacol Physiol 2001; 28: $285-289$.

28 Kaasinen V, Rinne JO: Functional imaging studies of dopamine system and cognition in normal aging and Parkinson's disease. Neurosci Biobehav Rev 2002; 26: 785-793.

29 Boomsma DI, de Geus EJ, Vink JM et al: Netherlands twin register: from twins to twin families. Twin Res Hum Genet 2006; 9: 849-857.

30 Polderman TJC, Gosso MF, Posthuma D et al: A longitudinal twin study on IQ, executive functioning, and attention problems during childhood and early adolescence. Acta Neurol Belg 2006; 106: 191-207.

31 Polderman TJC, Stins JF, Posthuma D, Gosso MF, Verhulst FC, Boomsma DI: The phenotypic and genotypic relation between working memory speed and capacity. Intelligence 2006; 34 : $549-560$.

32 Posthuma D, Luciano $\mathrm{M}$, Geus EJ et al: A genomewide scan for intelligence identifies quantitative trait loci on $2 \mathrm{q}$ and $6 \mathrm{p} . A m J$ Hum Genet 2005; 77: 318-326.

33 Hoekstra C, Meijer P, Kluft C et al: Genetics of dizygotic twinning: a feasibility study for a biobank. Twin Res 2004; 7: 556-563.

34 Wechsler D: Wechsler intelligence scale for children-revised (WISC-R). Lisse, Swets \& Zeitlinger 1986.

35 Wechsler D WAIS-III Wechsler Adult Intelligence Scale San Antonio, Texas, Psychological Corporation, 1997.

36 Meulenbelt I, Droog S, Trommelen GJ, Boomsma DI, Slagboom PE: High-yield noninvasive human genomic DNA isolation method for genetic studies in geographically dispersed families and populations. Am J Hum Genet 1995; 57: $1252-1254$.

37 Miller SA, Dykes DD, Polesky HF: A simple salting out procedure for extracting DNA from human nucleated cells. Nucleic Acids Res 1988; 16: 1215 .

38 Hirschhorn JN, Daly MJ: Genome-wide association studies for common diseases and complex traits. Nat Rev Genet 2005; 6: 95-108.

39 Gosso MF, de Geus EJ, van Belzen MJ et al: The SNAP-25 gene is associated with cognitive ability: evidence from a family-based study in two independent Dutch cohorts. Mol Psychiatry 2006; 11: 878-886.

40 Gosso MF, van Belzen M, de Geus EJ et al: Association between the CHRM2 gene and intelligence in a sample of 304 Dutch families. Genes Brain Behav 2006; 5: 577-584.

41 Abecasis GR, Cardon LR, Cookson WO: A general test of association for quantitative traits in nuclear families. Am J Hum Genet 2000; 66: 279-292. 
42 Fulker DW, Cherny SS, Sham PC, Hewitt JK: Combined linkage and association sib-pair analysis for quantitative traits. Am J Hum Genet 1999; 64: 259-267.

43 Posthuma D, de Geus EJ, Boomsma DI, Neale MC: Combined linkage and association tests in mx. Behav Genet 2004; 34: 179-196.

44 Harris SE, Wright AF, Hayward C, Starr JM, Whalley LJ, Deary IJ: The functional COMT polymorphism, Val 158 Met, is associated with logical memory and the personality trait intellect/imagination in a cohort of healthy 79 year olds. Neurosci Lett 2005; 385: 1-6.

45 Cools R, Robbins TW: Chemistry of the adaptive mind. Philos Transact A Math Phys Eng Sci 2004; 362: 2871-2888.

46 Bilder RM, Volavka J, Lachman HM, Grace AA: The catechol-Omethyltransferase polymorphism: relations to the tonic-phasic dopamine hypothesis and neuropsychiatric phenotypes. Neuropsychopharmacology 2004; 29: 1943-1961.

47 Winterer G, Weinberger DR: Genes, dopamine and cortical signal-to-noise ratio in schizophrenia. Trends neurosci 2004; 27: $683-690$.
48 Weinberger DR, Egan MF, Bertolino A et al: Prefrontal neurons and the genetics of schizophrenia. Biol Psychiatry 2001; 50: 825-844.

49 Gottfries CG: Neurochemical aspects on aging and diseases with cognitive impairment. J Neurosci Res 1990; 27: 541-547.

50 Wong DF, Wagner Jr HN, Dannals RF et al: Effects of age on dopamine and serotonin receptors measured by positron tomography in the living human brain. Science 1984; 226: 1393-1396.

51 Suhara T, Fukuda H, Inoue O et al: Age-related changes in human D1 dopamine receptors measured by positron emission tomography. Psychopharmacology (Berl) 1991; 103: 41-45.

52 Volkow ND, Ding YS, Fowler JS et al: Dopamine transporters decrease with age. J Nucl Med 1996; 37: 554-559.

53 Tsai SJ, Yu YW, Lin CH, Chen TJ, Chen SP, Hong CJ: Dopamine D2 receptor and $N$-methyl-D-aspartate receptor $2 \mathrm{~B}$ subunit genetic variants and intelligence. Neuropsychobiology 2002; 45: 128-130.

54 Bertolino A, Blasi G, Latorre V et al: Additive effects of genetic variation in dopamine regulating genes on working memory cortical activity in human brain. J Neurosci 2006; 26: 3918-3922. 